Arq. Bras. Med. Vet. Zootec., v.56, n.2, p.168-174, 2004

\title{
Lesões histológicas no sistema nervoso central de cães com encefalite e diagnóstico molecular da infecção pelo vírus da cinomose canina
}

\author{
[Histopathological lesions in the central nervous system of dogs with encephalitis and molecular diagnosis \\ of canine distemper virus infection] \\ C.M.S. Gebara ${ }^{1}$, S.R. Wosiacki $^{1}$, F.J. Negrão ${ }^{1}$, A.A. Alfieri ${ }^{2}$, A.F. Alfieri ${ }^{2}$ \\ ${ }^{1}$ Programa de Pós-graduação em Ciência Animal-UEL-Londrina \\ ${ }^{2}$ Departamento de Medicina Veterinária Preventiva \\ Centro de Ciências Agrárias - Universidade Estadual de Londrina \\ Caixa Postal 6001 \\ 86051-990 - Londrina, PR
}

\begin{abstract}
RESUMO
Dez amostras de urina de cães que apresentavam sinais clínicos sistêmicos e neurológicos indicativos da infecção pelo vírus da cinomose canina (CDV) foram analisadas pela técnica da reação em cadeia pela polimerase precedida de transcrição reversa (RT-PCR) para a detecção do RNA do CDV. O exame histopatológico foi realizado em fragmentos de cérebro, cerebelo e bexiga. Como controle negativo foram colhidos fragmentos de órgãos e urina de quatro cães sem sinais clínicos de doença infecciosa e que morreram por outras causas. Todos os cães $(9 / 10)$ positivos em RT-PCR apresentaram alterações histológicas no cérebro e cerebelo, características de encefalite aguda (5/9) ou crônica (4/9) compatíveis com as causadas pelo CDV. Um dos cães com alterações clínicas neurológicas semelhantes às observadas em cinomose foi negativo na RT-PCR e apresentou alterações histopatológicas inespecíficas. Nas amostras de bexiga não foram observadas lesões histológicas. Todas as amostras biológicas provenientes dos cães-controle foram negativas na RT-PCR (urina) e não apresentaram alterações histológicas (fragmentos de órgãos). O trabalho evidenciou a especificidade da RT-PCR no diagnóstico precoce e ante mortem na infecção pelo CDV.
\end{abstract}

Palavras-chave: cão, cinomose canina, vírus da cinomose canina, RT-PCR, histopatologia

\begin{abstract}
The reverse transcription-polymerase chain reaction (RT-PCR) was used to detect canine distemper virus $(C D V)$ RNA in 10 urine samples from dogs that had died with clinical systemic and neurological signs indicative of $C D V$ infection. Brain, cerebellum and urinary bladder fragments were collected for histopathological examination. For the negative control, urine and organ fragments were collected at necropsy from four dogs without clinical symptoms of infectious diseases that had died from other causes. The dogs positives in RT-PCR (9/10) presented histological lesions in the brain and cerebellum characteristic of acute (5/9) or chronic (4/9) encephalitis compatible with those caused by CDV. One of the dogs with neurological signs similar to those observed in canine distemper was negative in RT-PCR and presented non-specific histopathological alterations that could be associated to others nervous system diseases. Although the RT-PCR detected the CDV in urine of nine dogs with clinical signs of distemper, no histopathological alterations were observed in any of the urinary bladder samples. All the biological samples from the control dogs were negative in RT-PCR and did not present any histopathological alterations in organ. Besides describing the most characteristic histopathological
\end{abstract}

Apoio financeiro: CNPq, CAPES e CPG/Universidade Estadual de Londrina (UEL)

Recebido para publicação em 25 de novembro de 2002

Recebido para publicação, após modificações, em 28 de abril de 2003

E-mail: alfieri@uel.br 
lesion found in the central nervous system of dogs with acute and chronic encephalitis due to canine distemper, this study also showed the specificity of the RT-PCR technique in early and ante mortem diagnosis of CDV infections.

Keywords: dog, canine distemper, canine distemper virus, RT-PCR, histopathology

\section{INTRODUÇÃO}

As enfermidades inflamatórias e infecciosas do sistema nervoso central (SNC) representam um importante grupo de doenças nos cães. Sinais clínicos graves, muitas vezes incompatíveis com a vida do animal, podem ser determinados por diferentes etiologias. $\mathrm{O}$ vírus da cinomose canina (canine distemper virus - CDV) é um importante patógeno que determina altas taxas de mortalidade, com letalidade inferior apenas à raiva canina (Shell, 1990; Tipold, 1995; Appel, Summers, 1995; Stettler, Zubriggen, 1995).

O CDV é um morbilivirus que pode infectar uma grande variedade de carnívoros, incluindo os membros da família Canidae. Apesar da infecção pelo CDV ocorrer em animais de todas as faixas etárias, os filhotes, com idade inferior a três meses, parecem ser os mais susceptíveis (Rude, 1987; Shell, 1990).

O grau de comprometimento do SNC é dependente da estirpe viral, da idade e da imunocompetência do cão. Animais jovens e cães com imunodeficiência, com freqüência, desenvolvem necrose neuronal. Cães adultos e imunocompetentes geralmente apresentam desmielinização (Shell, 1990). São descritas quatro formas de encefalite causada pelo CDV: 1- encefalite em cães jovens, de caráter grave e agudo, com manifestação simultânea de sinais clínicos sistêmicos e neurológicos; 2- encefalite em cães adultos, do tipo crônica, na qual os distúrbios neurológicos podem estar desacompanhados de transtornos sistêmicos; 3encefalite do cão velho e 4- encefalite recidivante crônica, que são de ocorrência esporádica (Braund, 1994).

Na dependência da região do SNC comprometida pelo CDV, os sinais neurológicos variam consideravelmente. No entanto, as convulsões e paralisias dos membros pélvicos, juntamente com sinais vestibulares, como ataxia e nistagmo, e cerebelares, como tremores e hipermetria, são os mais freqüentemente encontrados em cães com a forma neurológica da cinomose (Shell, 1990).

O diagnóstico da infecção pelo CDV é de difícil realização e geralmente é fundamentado nos sinais clínicos. Outro agravante é que 25 a $75 \%$ dos animais susceptíveis desenvolvem infecção subclínica e eliminam o vírus no ambiente, atuando como fontes de infecção (Shell, 1990; Appel Summers, 1999). O diagnóstico clínico pode ser confirmado pela identificação de corpúsculos de inclusão em células associadas a exudato, em células epiteliais e em neutrófilos, porém sua ausência não exclui a infecção pelo CDV (Motohashi et al., 1969; Greene, 1998; Jones et al., 2000).

As técnicas sorológicas apresentam valor diagnóstico limitado para o CDV uma vez que animais que morrem por cinomose podem ou não apresentar títulos mensuráveis de anticorpos (Appel, 1969; Appel, Summers, 1999; Frisk et al., 1999). A técnica de isolamento viral em cultivo celular é específica, porém demorada e pode resultar em falso-negativo se o animal não estiver na fase aguda da doença (Shin et al., 1995).

No SNC o CDV causa lesões principalmente no cerebelo e nas colunas brancas da medula espinhal, caracterizadas por áreas de necrose bem delimitadas, desmielinização e inclusões intranucleares principalmente em astrócitos. A observação dessas lesões confirma o diagnóstico da infecção pelo CDV, porém este é um método de diagnóstico post mortem (Greene, 1998; Jones et al., 2000).

Atualmente, a técnica da reação em cadeia pela polimerase precedida de transcrição reversa (RTPCR) vem sendo empregada com sucesso na detecção do CDV em diferentes tipos de amostras biológicas provenientes de cães com sinais clínicos sistêmicos e neurológicos (Frisk et al., 1999; Shin et al., 1995; Saito, 2001; Gebara, 2002). O objetivo deste trabalho foi avaliar histologicamente fragmentos de SNC e de bexiga 
de cães com diagnóstico laboratorial de cinomose canina realizado pela técnica da RTPCR.

\section{MATERIAL E MÉTODOS}

Dez cães, previamente avaliados pela técnica da RT-PCR para o diagnóstico do CDV, foram distribuídos em dois grupos (A e B) de acordo com a faixa etária (menos de seis meses e acima de 12 meses) e a presença de sinais clínicos sistêmicos e neurológicos (Tab. 1). Por sonda vesical ou micção espontânea, foram colhidos aproximadamente $3 \mathrm{ml}$ de urina de cada cão. $\mathrm{O}$ material foi armazenado à $4^{\circ} \mathrm{C}$ e processado em no máximo 48 horas. Durante a necropsia, foram colhidos fragmentos de cérebro, cerebelo e bexiga para a realização do exame histopatológico. Como controle negativo foram incluídos fragmentos de órgãos e urina provenientes de quatro cães que não apresentavam sinais clínicos de doenças infecciosas e que morreram por outras causas.

Tabela 1. Distribuição dos animais com sinais clínicos sugestivos da cinomose canina, de acordo com o resultado da técnica da reação em cadeia pela polimerase com transcrição reversa (RT-PCR), dos sinais clínicos e da faixa etária

\begin{tabular}{|c|c|c|c|c|}
\hline \multirow[b]{2}{*}{ Grupo } & \multicolumn{2}{|c|}{ RT-PCR } & \multicolumn{2}{|c|}{ Sinal clínico } \\
\hline & Positiva & Negativa & Neurológico & $\begin{array}{l}\text { Neurológico e } \\
\text { sistêmico }\end{array}$ \\
\hline A & 5 & - & - & 5 \\
\hline B & 4 & $1^{\mathrm{a}}$ & 2 & 3 \\
\hline Total & 9 & 1 & 2 & 8 \\
\hline
\end{tabular}

Os fragmentos de órgãos, fixados em formalina a $10 \%$ tamponada, foram desidratados, diafanizados e embebidos em parafina. Cortes histológicos de 4 a $5 \mu \mathrm{m}$ foram corados em HE para o diagnóstico histopatológico sob microscopia óptica segundo Behmer et al. (1976).

A extração do RNA do CDV foi realizada a partir de uma alíquota de $300 \mu l$ de urina de acordo com a técnica da sílica/tiocianato de guanidina descrita por Boom et al. (1990). O ácido nucléico foi eluído à temperatura de $56^{\circ} \mathrm{C}$ em $40 \mu 1$ de água ultrapura estéril, tratada com
$1 \mu \mathrm{l}$ (26 unidades/ $\mu \mathrm{l}$ ) de inibidor de RNAse ${ }^{1}$. Todas as amostras foram mantindas à $-20^{\circ} \mathrm{C}$ até a sua utilização na técnica da RT-PCR.

Para a realização da RT-PCR foram utilizados os oligonucleotídeos iniciadores CDV1 (+) [5'-aca gga ttg ctg agg acc tat-3', nt 769-789] e CDV2 (-) [5'-caa gat aac cat gta cgg tgc-3', nt.10551035], desenhados a partir da seqüência do gene que codifica a nucleoproteína do CDV e que amplificam um produto de $287 \mathrm{pb}$ (Frisk et al., 1999). A transcrição reversa foi realizada à $37^{\circ} \mathrm{C}$ por uma hora, em um volume final de $20 \mu$, composto por $5 \mu \mathrm{l}$ de RNA, 0,4pmol do primer CDV1, 0,125mM de cada dNTP ${ }^{2}, 200$ unidades da enzima $M-M L V^{2}$ em tampão fornecido pelo fabricante. Para a PCR, foram utilizados $2 \mu \mathrm{l}$ do cDNA, 0,4pmol dos primers CDV1 e CDV2, $1,5 \mathrm{mM}$ de $\mathrm{MgCl}_{2}$ e 2,5 unidades de Taq DNA polimerase ${ }^{2}$ em tampão fornecido pelo fabricante e água ultrapura estéril para um volume final de $50 \mu 1$. A reação foi realizada nas seguintes condições de tempo e temperatura: $1 \mathrm{~min} / 94^{\circ} \mathrm{C}$; 40 ciclos de $1 \mathrm{~min} / 94^{\circ} \mathrm{C}, 2 \mathrm{~min} / 59^{\circ} \mathrm{C}, 1 \mathrm{~min} / 72^{\circ} \mathrm{C}$, seguidos de extensão final de $7 \mathrm{~min} / 72^{\circ} \mathrm{C}$.

Todas as reações foram realizadas na presença de controles negativos, representados por urina de cães assintomáticos e água ultrapura estéril. Como controle positivo foi utilizada a estirpe viral Rockborn do CDV produzida em cultivo de células Madin Darby canine kidney (MDCK).

A especificidade dos produtos amplificados na RTPCR foi avaliada pela análise do perfil de restrição com a enzima Hinf I (10 unidades/ $\mu)^{2}$, selecionada pela análise no software Gene Runner (disponível em http://www.generunner.com). A clivagem dos amplicons foi realizada de acordo com as recomendações do fabricante.

Os produtos amplificados pela RT-PCR e os clivados com a enzima de restrição foram analisados por eletroforese em gel de agarose a 2\% em tampão TBE pH 8.4 (TRIS 89 mM, ácido bórico $89 \mathrm{mM}$, EDTA $2 \mathrm{mM}$ ), corado com brometo de etídeo $(0,5 \mu \mathrm{l} / \mathrm{ml})$ e visualizado sob luz ultravioleta.

\footnotetext{
${ }^{1}$ RNAguard-Pharmacia Biotech ${ }^{\circledR}$.

${ }^{2}$ Invitrogen ${ }^{\text {TML Life Technology }}$
} 


\section{RESULTADOS E DISCUSSÃO}

A técnica da RT-PCR realizada em 10 amostras de urina possibilitou a amplificação de um fragmento de cDNA com $287 \mathrm{pb}$ em nove amostras. A especificidade dos amplicons foi confirmada pela análise com a enzima de restrição Hinf I que gerou, conforme o esperado, dois fragmentos com 227 e $60 \mathrm{pb}$ (Fig. 1).
Todos os cães apresentaram sinais clínicos sistêmicos e neurológicos, descritos por Rude (1987) e Shell (1990) como sugestivos da infecção pelo CDV. Os sinais clínicos e respectivas freqüências são apresentados na Tab. 2 , de acordo com o grupo de idade dos cães.

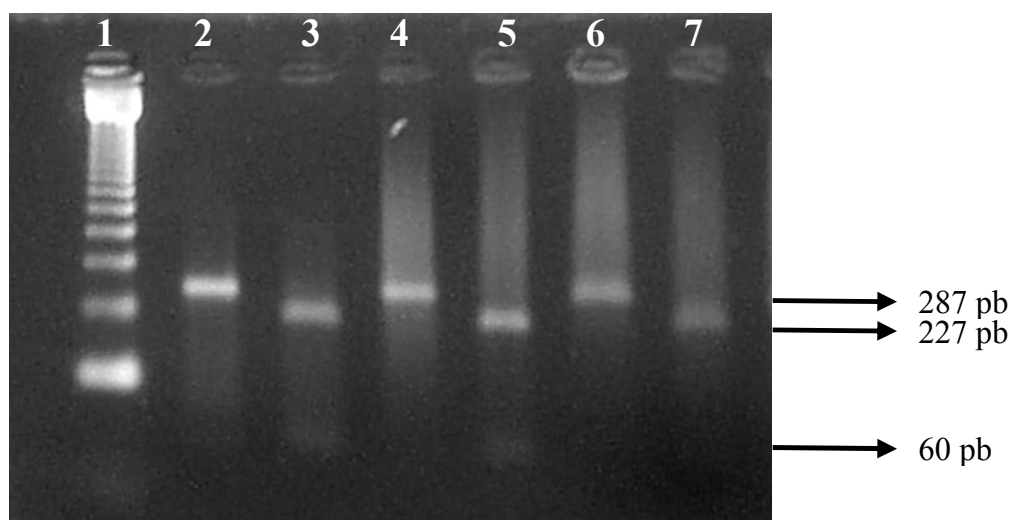

Figura 1. Eletroforese em gel de agarose dos produtos amplificados pela técnica da RT-PCR para a detecção do vírus da cinomose canina e dos fragmentos de restrição dos amplicons clivados com a enzima Hinf I. Canaleta

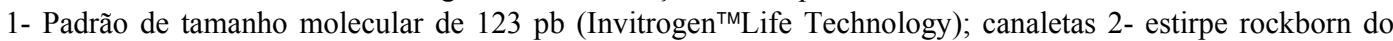
vírus da cinomose canina (controle positivo); canaletas 4 e 6- amostras de urina de cães dos grupos A (4) e $\mathrm{B}(6)$; canaletas 3, 5 e 7- amostras clivadas com a enzima Hinf I referentes às canaletas 2, 4 e 6.

Tabela 2. Sinais clínicos observados em nove cães com diagnóstico positivo para o vírus da cinomose canina realizado pela técnica da RT-PCR

\begin{tabular}{|c|c|c|}
\hline Grupo & Sinal Clínico & $\mathrm{N}$ \\
\hline $\mathrm{A}^{(1)}$ & 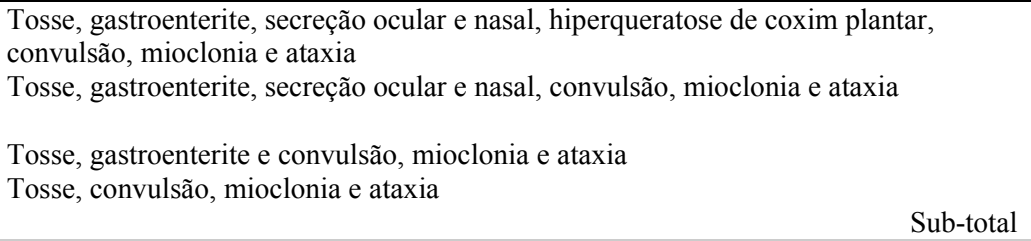 & $\begin{array}{l}1 \\
1 \\
1 \\
5\end{array}$ \\
\hline Total & $\begin{array}{l}\text { Secreção ocular e nasal, tosse, convulsão e mioclonia } \\
\text { Secreção ocular e nasal, convulsão, mioclonia e ataxia } \\
\text { Convulsão, mioclonia e ataxia }\end{array}$ & $\begin{array}{l}1 \\
2 \\
1 \\
4 \\
9\end{array}$ \\
\hline
\end{tabular}

(1) Animais jovens: idade inferior a seis meses.

(2) Animais adultos: idade superior a 12 meses.

Segundo Jones et al. (2000), no SNC o CDV tem afinidade pelos tecidos mielinizados do cérebro e da medula espinhal. Contrastando com outras infecções, na cinomose os neurônios não são primariamente afetados. Portanto, a distribuição e a natureza das lesões diferem das observadas na maioria das outras encefalites.

As alterações histológicas observadas em cérebro e cerebelo dos cães com infecção pelo $\mathrm{CDV}$, 
confirmada pela RT-PCR, são apresentadas na Tab. 3. A Fig. 2 mostra as lesões mais freqüentes, caracterizadas por áreas de desmielinização, necrose, manguito perivascular e corpúsculo de inclusão, encontradas em cerebelo.

Tabela 3. Alterações histopatológicas em cérebro e cerebelo de cães com diagnóstico positivo para o virus da cinomose canina realizado pela técnica da RT-PCR

\begin{tabular}{|c|c|c|}
\hline \multirow{2}{*}{ Grupo } & \multicolumn{2}{|c|}{ Alteração } \\
\hline & Cérebro & Cerebelo \\
\hline $\mathrm{A}^{(1)}$ & $\begin{array}{l}\text { Desmielinização multifocal moderada da } \\
\text { substância branca, astrogliose moderada, } \\
\text { pequenos manguitos perivasculares, } \\
\text { corpúsculos eosinofílicos e intranucleares em } \\
\text { astrócitos }\end{array}$ & $\begin{array}{l}\text { Desmielinização multifocal intensa da substância } \\
\text { branca, pequenos manguitos perivasculares } \\
\text { formados por uma a duas camadas de células } \\
\text { mononucleadas, pequenas áreas de necrose da } \\
\text { substância branca, astrogliose e astrocitose discreta } \\
\text { a moderada associada a corpúsculos de Sinegaglia- } \\
\text { Lentz em astrócitos }\end{array}$ \\
\hline
\end{tabular}

Desmielinização multifical moderada, grandes manguitos perivasculares formados por quatro a

$\mathrm{B}^{(2)}$ cinco camadas de células mononucleares, astrogliose e astrocitose
Desmielinização multifical intensa da substância branca, grandes manguitos perivasculares formados por quatro a cinco camadas de células mononucleadas, astrocitose, degeneração de algumas células de Purkinjie associada a corpúsculos de Sinegaglia-Lentz em astrócitos

(1) Animais jovens: idade inferior a seis meses.

(2) Animais adultos: idade superior a doze meses.
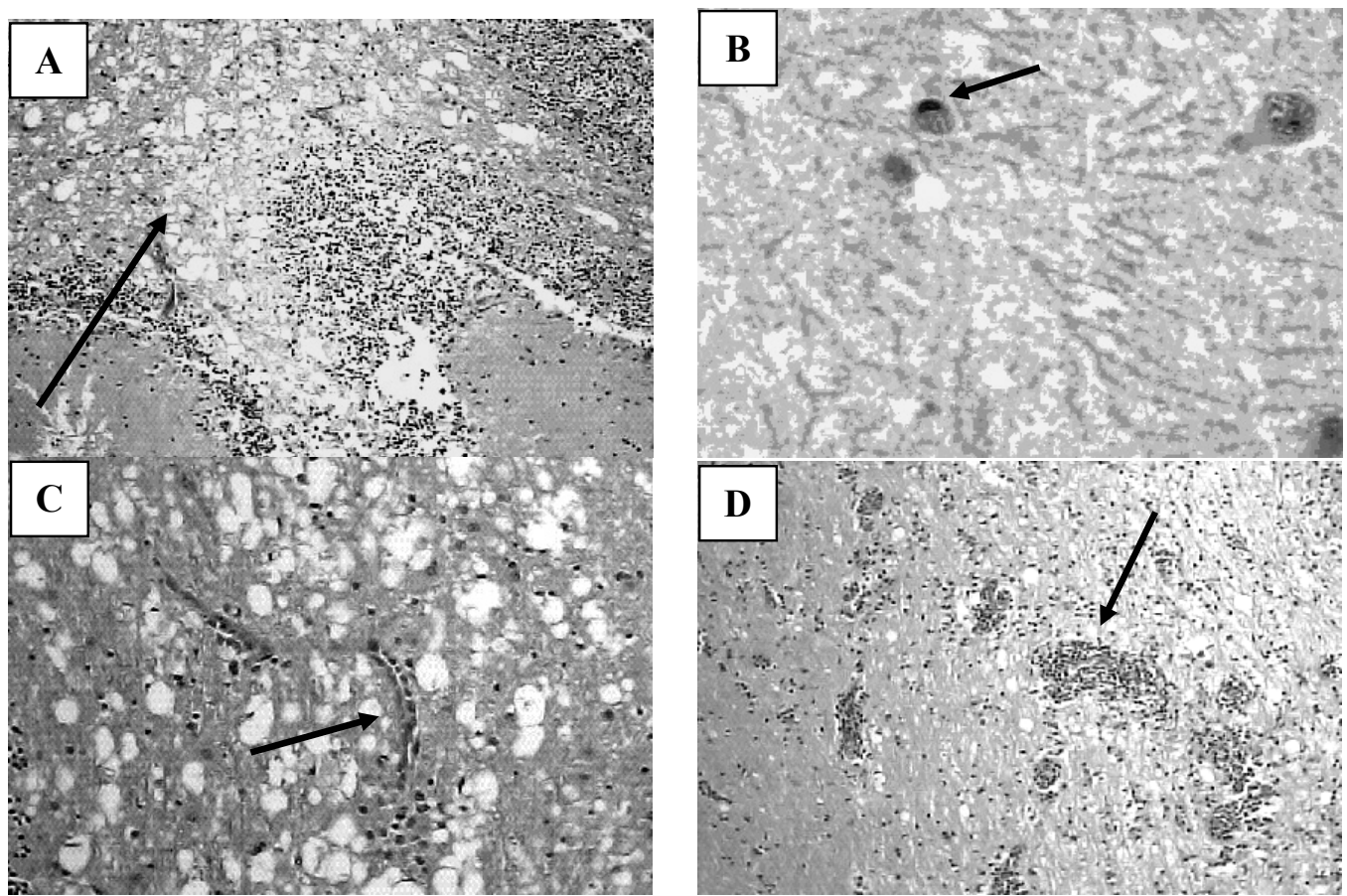

Figura 2. Fotomicrografia de cerebelo de cão com sinal clínico neurológico e com diagnóstico etiológico positivo para o vírus da cinomose canina realizado pela técnica da RT-PCR. Painel A- áreas de desmielinização e necrose. HE, obj. 10×. Painel B- Corpúsculos de inclusão em núcleo de astrócitos. HE, obj. 40×. Painel Cáreas de desmielinização, necrose e manguito perivascular formado por uma camada de células mononucleadas. HE, obj. 20×. Painel D- áreas de desmielinização, necrose e manguito perivascular formados por quatro a cinco camadas de células mononucleadas. HE, obj. $40 \times$. 
A encefalite aguda determinada pelo CDV, observada nos cães do grupo $\mathrm{A}$, ocorre mais freqüentemente em cães jovens e geralmente é acompanhada de sinais clínicos sistêmicos. O exame histopatológico revelou encefalite desmielinizante multifocal aguda, grave e com necrose da substância branca. A desmielinização da substância branca, áreas de necrose, presença de corpúsculos de inclusão em astrócitos e infiltrados perivasculares são achados histopatológicos freqüentes na cinomose (Carlton, McGavin, 1998; Jones et al., 2000). Encefalite desmielinizante com corpúsculos de inclusão em astrócitos, característicos do CDV, também foi encontrada em $82 \%(205 / 250)$ das amostras provenientes de cães com cinomose analisadas por Headley e Graça (2000).

No grupo B, quatro dos cinco cães foram positivos na RT-PCR e apresentaram encefalite crônica. As lesões nessa faixa etária foram multifocais com intensa desmielinização, indicando encefalite desmielinizante multifocal crônica, grave e associada a corpúsculos eosinofílicos intranucleares em astrócitos. Os cães que desenvolvem esse tipo de lesão apresentam aumento no título de anticorpos contra o $\mathrm{CDV}$ e, com freqüência, não manifestam sinais clínicos sistêmicos (Rude, 1987; Shell 1990; Appel, Summers, 1999; Headley, Graça, 2000).

Os astrócitos são as células-alvo do vírus no SNC e estão envolvidos no processo de desmielinização que ocorre na encefalite aguda e crônica observada em cães e outros carnívoros com infecção pelo CDV (Zubriggen et al., 1995; Carlton, McGavin, 1998; Headley et al., 2001). Em nove cães positivos na RT-PCR para o CDV foram observados processos de astrogliose $\mathrm{e}$ astrocitose no cérebro e no cerebelo.

Por apresentar ataxia e convulsões, sinais clínicos comuns na cinomose, um cão do grupo $\mathrm{B}$, negativo para o CDV na RT-PCR, também foi incluído neste estudo. $\mathrm{O}$ exame histopatológico revelou hiperemia multifocal no neurobilo e nos vasos da meninge; no cérebro e no cerebelo foram observadas pequenas áreas de hemorragia e manguitos perivasculares. Essas alterações, consideradas inespecíficas, podem ser encontradas em outras enfermidades que determinam lesões no SNC como raiva, toxoplasmose, criptococose, erliquiose e neosporose (Jones et al., 2000).

Corpúsculos de inclusão intracitoplasmáticos e/ou intranucleares no epitélio vesical, aliados à hiperemia, são alterações que podem estar presentes na infecção pelo CDV (Jones et al., 2000). Essas alterações foram evidenciadas na bexiga de apenas 15\% (39/250) das amostras positivas para cinomose canina analisadas por Headley e Graça (2000). Neste trabalho, apesar da RT-PCR ter sido realizada a partir da urina, nenhuma alteração histológica foi observada na bexiga dos cães positivos. Este resultado pode ter sido influenciado pelo número e local dos cortes histológicos avaliados, bem como pela falta de tempo hábil, após a infecção, para o desenvolvimento de lesões no epitélio vesical.

Não foi encontrada alteração histológica no cérebro, no cerebelo e na bexiga dos quatro cães assintomáticos e negativos na RT-PCR, incluídos neste estudo como grupo-controle.

Os resultados revelaram que houve concordância entre as características das lesões histológicas, a idade dos cães e a forma clínica da cinomose canina com os resultados da RT-PCR. Essa técnica possibilitou a detecção do ácido nucléico do CDV na urina de cães tanto com encefalite aguda quanto crônica, evidenciando a virúria, mesmo não sendo encontradas alterações histológicas na bexiga. Estes resultados demonstraram ainda que a técnica de RT-PCR foi um método eficiente para a realização do diagnóstico rápido, precoce e, principalmente, ante mortem das formas sistêmica e neurológica da infecção pelo CDV.

\section{REFERÊNCIAS BIBLIOGRÁFICAS}

ANDERSON, E.C. Morbillivirus infections in wildlife (in relation to their population biology and disease control in domestic animals). Vet. Microbiol., v.44, p.319-332, 1995.

APPEL, M.J.G. Pathogenesis of canine distemper. Am. J. Vet. Res., v.30, p.1167-1182, 1969.

APPEL, M.J.G.; SUMMERS, B.A. Canine distemper: Current Status, 1999. Disponível em: 
$<$ http://www.ivis.org/> Acesso em: 13 mar. 2002.

APPEL, M.J.G.; SUMMERS, B.A. Pathogenicity of morbilliviruses for terrestrial carnivores. Vet. Microbiol., v.44, p.187-191, 1995.

BEHMER, O.A.; TOLOSA, E.M.C.; FREITAS, N.A.G. Manual de técnicas para histologia normal e patológica. São Paulo: EDART, 1976. 241p.

BOOM, R.; SOL, C.J.A.; SALIMANS, M.M.M. et al. Rapid an simple method for purification of nucleic acids. J. Clin. Microbiol., v.28, p.495503, 1990 .

BRAUND, K.G. Clinical syndromes in veterinary neurology. 2.ed. St. Louis: Mosby, 1994. $477 \mathrm{p}$.

CARLTON, W.W.; McGAVIN, M. Patologia veterinária especial. 2.ed. Porto Alegre: ArtMed. 1998. 672p.

FENNER, F. Veterinary virology. Londres: Academic Press, 1987. 445p.

FRISK, A.L.; KONIG, M.; MORITZ, A. et al. Detection of canine distemper virus nucleoprotein RNA by reverse transcription-PCR using serum, whole blood, and cerebrospinhal fluid from dogs with distemper. J. Clin. Microbiol., v.37, p.3634-3643, 1999.

GEBARA, C.M.S. Achados clínicos $e$ histopatológicos em cães com diagnóstico molecular do vírus da cinomose canina. 2002. 94f. Dissertação (Mestrado em Sanidade Animal)- Centro de Ciências Agrárias, Universidade Estadual de Londrina, Londrina, PR.

GREENE, G.E. Infectious diseases of the dog and the cat. Philadelphia: W.B. Saunders, 1998. $820 \mathrm{p}$.

HEADLEY, S.A.; GRAÇA, D.L. Canine distemper: epidemiological findings of 250 cases. Braz. J. Vet. Res. Anim. Sci., v.37, p.136140,2000

HEADLEY, S.A.; GRAÇA, D.L.; SOARES, I.C. Glial fibrillary acidic protein (GFAP) immunoreactive astrocytes in dogs infected with canine distemper virus. J. Comp. Pathol., v.125, p.90-97, 2001.

JONES, C.T.; HUNT, D. H.; KING, N.W. Patologia veterinária. São Paulo: Manole, 2000. 1415p.

MOTOHASHI, T.; NAKAGAWA, H.; OKADA, $\mathrm{T}$. Fluorescent antibody technique in diagnosis of canine distemper. Vet. Med. Small Anim. Clin., v.65, p.1057-1059, 1969.

RUDE, T.A. Canine distemper vírus: Infection and prevention. Canine Pract., v.14, p.16-24, 1987.

SAITO, T.B. Padronização da técnica da Reação em Cadeia pela Polimerase (RT-PCR) para o diagnóstico ante e post mortem do virus da cinomose canina. Londrina, 2001. 100f. Dissertação (Mestrado em Sanidade Animal)Centro de Ciências Agrárias, Universidade Estadual de Londrina, Londrina, PR.

SHELL, L.G. Canine distemper. Comp. Small Anim., v.12, p.173-179, 1990.

SHEN, D.T.; GORHAM, J.R.; PERDERSEN, V. Viriuria in dogs infected with canine distemper. Vet. Med. Small Anim. Clin., v.76, p.1175-1177, 1981.

SHIN, Y.; MORI, T.; OKITA, M. et al. Detection of canine distemper virus nucleocapsid protein gene in canine peripheal blood mononuclear cells by RT-PCR. J. Vet. Med. Sci., v.57, p.439-45, 1995.

STETTLER, M.; ZUBRIGGEN, A. Nucleotide and deduced aminoacid sequences of the nucleocapsid protein of the virulent A75/17CDV strain of canine distemper virus, Vet. Microbiol., v.44, p.211-217, 1995.

TIPOLD, A. Diagnosis of inflamatory and infectious diseases of the central nervous system in dogs: a retrospective study. J. Vet. Int. Med., v.9, p.304-314, 1995.

ZUBRIGGEN, A.; GRABER, H.U.; VANDELVEDE, M. Seletive spread and reduced virus release leads to canine distemper virus persistence in the nervous system. Vet. Microbiol., v.44, p.281-288, 1995. 